\title{
ANALISIS KEPUASAN PENGUNJUNG PROGRAM AGROEDUWISATA TAMAN TEKNOLOGI PERTANIAN (TTP) CIGOMBONG, KABUPATEN BOGOR
}

\author{
Dara Puspita Sari1), Ahyar Ismail2), dan Burhanuddin ${ }^{3)}$ \\ 1,2)Departemen Ekonomi Sumberdaya dan Lingkungan, Fakultas Ekonomi dan Manajemen, \\ Institut Pertanian Bogor \\ 3)Departemen Agribisnis, Fakultas Ekonomi dan Manajemen, Institut Pertanian Bogor \\ Jl. Agatis Wing 3 Level 2, Kampus IPB Darmaga Bogor, Indonesia \\ e-mail: 1)dara.psaj@gmail.com
}

(Diterima 21 April 2021 / Revisi 5 Juni 2021 / Disetujui 22 Juni 2021)

\begin{abstract}
Along with the Indonesian government project to develop science technopark, the Ministry of Agriculture of Indonesia has established Cigombong Agricultural Technopark (ATP). Agroeduwisata program is one of the Cigombong Agricultural Techno Park (ATP) programs as a tool for agricultural technology dissemination as well as become one of the business units for income-generating. To increase the number of visitors, the manager should explore the existing weaknesses and strengths to define the priorities of improvement to increase the visitor's satisfaction. This study aims (1) to measure the satisfaction level of visitors on the Cigombong ATP agroeduwisata program, and (2) to identify the importance and performance level of the program. The research was conducted in September-October 2020 by a survey of 34 visitors to the Cigombong ATP agroeduwisata program. A descriptive analysis was developed by using the Customer Satisfaction Index (CSI) and Importance Performance Analysis (IPA). The results suggested that visitors were satisfied with a CSI value of 78.79 per cent. Furthermore, according to IPA, the improvement of the safety of location and accommodation facilities should be prioritized and further developed Meanwhile, the attributes including the benefits of agroeduwisata, the responsiveness of services, comfort of the location, politeness and friendliness. guides, ease of communication for carrying out activities, agroeduwisata activity packages offered, supporting facilities, consumption facilities and tidiness of guides were found to perform quite good and therefore should be consistently maintained. In addition, the attributes such as ticket prices, promotions, the response of complaints and access to the location were found to be less prioritized.
\end{abstract}

Keywords: agroeduwisata program, cigombong ATP, IPA, visitors satisfaction

\begin{abstract}
ABSTRAK
Seiring dengan program pemerintah Indonesia untuk mengembangkan science technopark, Kementerian Pertanian telah membangun Taman Teknologi Pertanian (TTP) Cigombong. Program agroeduwisata merupakan salah satu program Taman Teknologi Pertanian (TTP) Cigombong sebagai sarana diseminasi teknologi pertanian sekaligus menjadi salah satu unit usaha penghasil pendapatan. Untuk meningkatkan jumlah pengunjung, pengelola harus menggali kelemahan dan kekuatan yang ada untuk menentukan prioritas perbaikan untuk meningkatkan kepuasan pengunjung. Penelitian ini bertujuan (1) mengukur tingkat kepuasan pengunjung program agroeduwisata TTP Cigombong, (2) mengidentifikasi tingkat kepentingan dan kinerja program. Penelitian dilakukan pada Bulan SeptemberOktober tahun 2020 dengan survei terhadap 34 pengunjung program agroeduwisata TTP Cigombong. Analisis deskriptif dikembangkan dengan menggunakan Customer Satisfaction Index (CSI) dan Importance Performance Analysis (IPA). Hasil penelitian menunjukkan pengunjung merasa puas dengan nilai CSI sebesar 78,79 persen. Selanjutnya, menurut IPA, peningkatan keamanan lokasi dan fasilitas penginapan menjadi harus diprioritaskan dan dikembangkan lebih lanjut. Sedangkan atribut yang meliputi manfaat agroeduwisata, ketanggapan pemandu, kenyamanan lokasi, kesopanan dan keramahan pemandu, kemudahan komunikasi untuk penyelenggaraan kegiatan, paket kegiatan agroeduwisata yang ditawarkan, fasilitas penunjang, fasilitas konsumsi serta kerapihan pemandu yang dinilai telah berkinerja cukup baik sehingga harus terus dipertahankan. Selain itu, atribut seperti harga tiket, promosi, respons terhadap keluhan pengunjung dan kemudahan akses transportasi mencapai lokasi ditemukan tidak menjadi prioritas untuk diperbaiki.
\end{abstract}

Kata kunci: cigombong ATP, IPA, kepuasan pengunjung, program agrowisata 


\section{PENDAHULUAN}

Penguasaan, pemanfaatan, dan pemajuan ilmu pengetahuan dan teknologi sangat penting untuk memperkuat posisi global Indonesia sebagai negara berkembang (Rahayu \& Nurharjadmo, 2017). Oleh karena itu, pemerintah Indonesia melalui Badan Perencanaan dan Pembangunan Nasional (BAPPENAS) mengagendakan untuk membangun Taman Sains (Science Park) di 34 provinsi dan Taman Teknologi (Techno Park) di 100 kabupaten dalam waktu 5 tahun yang dituangkan dalam program quick win. Kementerian Pertanian (Kemetan) melalui Badan Penelitian dan Pengembangan Pertanian (Balitbangtan) mendapat tugas untuk membangun 17 Taman Sains Pertanian (Agro Science Park) di area Kebun Percobaan milik Balitbangtan dan 26 Taman Teknologi Pertanian (Agro Techno Park) di 26 Kabupaten (BPATP, 2015). Salah satu Taman Teknologi Pertanian (TTP) yang dibangun oleh Balitbangtan adalah TTP Cigombong.

Pengembangan TTP Cigombong merupakan kerja bersama antara Kementerian Pertanian, Pemda Kabupaten Bogor dan Institut Pertanian Bogor. Nota kesepahaman antara Bupati Bogor dan Kepala Badan Litbang Pertanian untuk pengembangan TTP ditandatangani pada tanggal 7 Mei 2015, melalui Nota Kesepahaman nomor 483/HK.220/I/05/2015 dan Nomor 119/10/V/ KB/KS/2015 (BPATP, 2017). TTP Cigombong dibangun pada pertengahan tahun 2015 menempati lahan pemda Kabupaten Bogor seluas \pm 8,4 hektar di Desa Tugujaya, Kecamatan Cigombong, Kabupaten Bogor.

Desa Tugu Jaya yang berada di kawasan di kaki Gunung Salak, selain sangat potensial pada sektor pertanian, perkebunan, perikanan dan perternakan juga potensial untuk pengembangan sektor pariwisata dengan konsep agrowisata (Ningsih dan Prawiranegara, 2016). Oleh karena itu, dalam salah satu target TTP Cigombong yang ditetapkan dalam grand design pembangunan TTP Cigombong adalah menjadi tujuan Wisata IPTEK Pertanian. Selain target tersebut, TTP Cigombong juga memiliki target dapat dikelola secara profesional, mandiri dan berkelanjutan. Dalam rangka mencapai kedua target tersebut TTP Cigombong memiliki dan melaksanakan program agroeduwisata. Konsep wisata dengan tema pendidikan pertanian atau yang dikenal dengan istilah agrowisata merupakan destinasi wisata yang cukup menarik bagi keluarga karena wisatawan-wisatawan juga mendapatkan edukasi mengenai tanaman dan pertanian selain mendapatkan kesenangan dari kegiatan wisata (Jeneetica, 2018).

Program agroeduwisata menjadi program yang cukup penting untuk dilaksanakan TTP Cigombong, karena melalui program ini TTP Cigombong dapat memerankan 2 (dua) fungsi sekaligus yaitu menjadi sarana untuk penyebaran IPTEK khususnya dibidang pertanian dan peternakan juga sebagai sarana TTP Cigombong untuk mendapatkan pendapatan. Oleh karena itu, perbaikan dan peningkatan kualitas pelayanan program agroeduwisata TTP Cigombong harus semakin ditingkatkan agar program agroeduwisata TTP Cigombong semakin diminati. Dalam rangka memperbaiki kinerja pelaksanaan program agroeduwisata TTP Cigombong yang telah dilaksanakan, diperlukan suatu evaluasi. Salah satu bentuk evaluasi sebagai suatu unit usaha tersebut adalah dengan mengevaluasi kepuasan konsumen terhadap kualitas produk atau pelayanan yang diberikan.

Kepuasan didefinisikan sebagai perasaan seseorang yang timbul setelah membandingkan harapan dengan kinerja atau hasil yang dirasakannya (Kotler, 2002). Kepuasan sebagai fungsi dari seberapa dekat harapan pembeli atas suatu produk dengan kinerja yang dirasakan pembeli atas produk tersebut. Jika kinerja produk lebih rendah daripada harapan, pembeli akan kecewa. Jika kinerja produk sesuai harapan, pembeli akan puas dan jika kinerja produk melebihi harapan, pembeli akan sangat puas.

Konsumen memiliki peran yang sangat penting bagi perkembangan dan pertumbuhan unit usaha. Tanpa konsumen, produk dan jasa yang dihasilkan suatu unit usaha tidak mungkin bisa terjual dan tidak memberikan keuntungan bagi unit usaha tersebut sehingga unit usaha tidak bisa berjalan (Sumarwan, 2014).

Dalam semua kegiatan perusahaan, kepuasan konsumen merupakan konsep sentral. Peningkatan kepuasan konsumen berpotensi memberikan pertumbuhan penjualan jangka 
pendek dan jangka panjang, serta pangsa pasar sebagai hasil dari pembelian ulang. Sebaliknya, ketidakpuasan konsumen akan memunculkan sejumlah risiko bagi sebuah perusahaan seperti protes dari lembaga konsumen atau pemboikotan, keluhan pelanggan, reaksi pesaing dan intervensi pemerintah (Tjiptono dan Chandra, 2012). Mengukur kepuasan konsumen sangat bermanfaat bagi suatu unit usaha diantaranya dapat digunakan untuk menyempurnakan kualitas pelayanan dan menyusun rencana kerja pada masa akan datang (Kotler, 2002).

Dalam kaitannya dengan pariwisata, konsumen program agroeduwisata TTP Cigombong adalah pengunjung. Menilai kepuasan pengunjung artinya menilai suatu pikiran dan keadaan emosi setelah pengujung melaksanakan kegiatan wisata (Baker dan Crompton, 2000). Berdasarkan pemaparan di atas, maka penelitian ini memiliki tujuan yaitu: (1) mengukur tingkat kepuasan pengunjung program agroeduwisata TTP Cigombong, dan (2) mengidentifikasi tingkat kepentingan pengunjung dan tingkat kinerja program agroeduwisata TTP Cigombong.

\section{METODE}

\section{METODE PENGAMBILAN SAMPEL}

Penelitian dilakukan pada Bulan September-Oktober tahun 2020, terkait adanya pandemi Covid-19, agroeduwisata TTP Cigombong dinon-aktifkan untuk sementara, sehingga penelitian dilakukan secara online terhadap pengunjung agroeduwisata yang nomor kontaknya dimiliki Manajer TTP Cigombong karena menjadi koordinator atau kontak person pada saat melakukan kegiatan agroeduwisata di TTP Cigombong. Berdasarkan data dari TTP Cigombong, pada tahun 2019 terdapat 50 jumlah kegiatan agroeduwisata dengan jumlah pengunjung sebanyak 1.740 orang, di mana sebagian besar pengunjung adalah murid sekolah Taman Kanakkanak (TK) dan Sekolah Dasar (SD).

Metode pengambilan sampel pada penelitian ini menggunakan pendekatan nonprobability sampling, yaitu setiap anggota populasi tidak memiliki kesempatan yang sama untuk dipilih. Teknik pengambilan sampel yang dipilih menggunakan purposive sampling yaitu teknik pengambilan sampel yang di dasarkan pada ciri atau karakteristik. Responden adalah pengunjung program agroeduwisata TTP Cigombong dengan kriteria telah melakukan kunjungan minimal satu kali, memiliki usia minimal 17 tahun dengan pertimbangan bahwa pada umur tersebut dapat dikatakan mampu mengambil keputusan secara rasional dan nomor kontaknya terdapat pada Manajer TTP Cigombong. Jumlah sampel yang diambil sebanyak 34 orang. Pengambilan jumlah sampel tersebut di atas 30 sampel yang merupakan sebaran normal pada statistik, ini dilakukan untuk menghindari sampel error atau tidak menyebar dengan normal (Sugiarto, 2003).

\section{METODE ANALISI DATA \\ Analisis Deskriptif}

Metode deskriptif adalah suatu metode yang berfungsi untuk memberi gambaran atau mendeskripsikan objek yang diteliti melalui data atau sampel yang telah terkumpul sebagaimana adanya tanpa melakukan analisis dan membuat kesimpulan yang berlaku untuk umum (Sugiyono, 2011). Analisis deskriptif akan digunakan untuk mendeskripsikan gambaran umum tempat penelitian, karakteristik pengunjung dan menguraikan data hasil analisis.

\section{Analisis Kepuasan Konsumen}

1. Dimensi dan Atribut Kualitas Pelayanan

Program agroeduwisata TTP Cigombong sebagai penyedia jasa harus mampu memberikan perhatian penuh pada service quality (SERVQUAL) sehingga tujuan pengunjung dapat terpenuhi. Menurut Tjiptono (2006) kualitas pelayanan mempunyai hubungan yang erat dengan kepuasan konsumen. Kualitas memberikan suatu dorongan kepada konsumen untuk menjalin hubungan yang kuat dengan perusahaan. Pada jangka panjang ikatan seperti ini memungkinkan perusahaan untuk memahami harapan serta kebutuhan konsumen.

Dalam konteks pengukuran variabel kualitas pelayanan, berdasarkan serangkaian penelitian Parasuraman, et al (1988) mengidentifikasi dan menyimpulkan terdapat 5 (lima) dimensi ukuran kualitas layanan. Penilaian kepuasan pengunjung program 
agroeduwisata TTP Cigombong menggunakan 15 (lima belas) atribut yang didasarkan pada dimensi ukuran kualitas layanan menurut Parasuraman, et al (1988), dengan pengelompokkan sebagai berikut:

Tabel 1. Dimensi dan Atribut Penilaian Kepuasan Pengunjung

\begin{tabular}{ll}
\hline \multicolumn{1}{c}{ Dimensi } & \multicolumn{1}{c}{ Atribut } \\
\hline Price & Harga Tiket \\
\hline Realibility & Manfaat agroeduwisata \\
\cline { 2 - 2 } & Promosi \\
\hline Responsiveness & Kecepatan pemandu \\
& melayani pengunjung \\
\cline { 2 - 2 } & Respons terhadap \\
& keluhan pengunjung \\
\hline Assurance & Kenyamanan lokasi \\
\cline { 2 - 2 } & Keamanan lokasi, \\
\cline { 2 - 2 } & Kesopanan dan \\
& keramahan pemandu \\
\hline Emphaty & Kemudahan komunikasi \\
\cline { 2 - 2 } & Kemudahan akses \\
& transportasi \\
\hline Tangible & Paket agroeduwisata \\
\cline { 2 - 2 } & Fasilitas penunjang \\
\cline { 2 - 2 } & Fasilitas konsumsi \\
\cline { 2 - 2 } & Fasilitas penginapan \\
\cline { 2 - 2 } & Kerapihan pemandu \\
\hline
\end{tabular}

2. Customer Satisfaction Index (CSI)

CSI merupakan suatu skala pengukuran yang menggambarkan tingkat kepuasan konsumen terhadap suatu produk. Menurut Aritonang (2005) CSI digunakan untuk mengetahui tingkat kepuasan konsumen secara menyeluruh dengan melihat tingkat kepentingan dari atribut-atribut produk.

Pengukuran terhadap CSI diperlukan karena hasil dari pengukuran dapat digunakan sebagai acuan untuk menentukan sasaran di tahun-tahun mendatang (Irawan, 2003). Cara menghitung indeks kepuasan konsumen (Aritonang, 2005), yaitu:

a. Menentukan Mean Imprtance Score (MIS) dan Mean Satisfication Score (MSS):

$$
\begin{gathered}
M I S=\frac{\left[\sum_{i=1}^{n} Y_{i}\right]}{n} \\
M S S=\frac{\left[\sum_{i=1}^{n} X_{i}\right]}{n}
\end{gathered}
$$

b. Menghitung Weighted Factor (WF), dengan rumus:

$$
W F_{i}=\frac{M I S_{i}}{\sum_{i=1}^{p} M I S_{i}} \times 100 \%
$$

c. Menghitung Weighting Score (WS), rumus:

$$
W S_{i}=W F_{i} \times M S S_{i}
$$

d. Menentukan CSI, dengan rumus:

$$
C S I=\frac{\sum_{i=1}^{p} W S_{i}}{H S} \times 100 \%
$$

Keterangan:

$\mathrm{n}$ = jumlah responden,

$\mathrm{Y}_{\mathrm{i}}=$ nilai harapan atribut ke $\mathrm{i}$

$\mathrm{X}_{\mathrm{i}}=$ nilai kinerja atribut ke $\mathrm{i}$

$\mathrm{P}=$ atribut $\mathrm{ke}-\mathrm{p}$

$\mathrm{HS}=$ skala maksimum yang digunakan (skala 5).

Berdasarkan Simamora (2004), untuk membuat skala linier numerik, pertamatama kita cari rentang skala (RS):

$$
R s=\frac{m-n}{b}
$$

Dimana:

$\mathrm{m}=$ Skor tertingggi

$\mathrm{n}$ = Skor terendah

$\mathrm{b}=$ Jumlah kelas yang dibuat

Rs $=$ Rentang skala

Pada penelitian ini, rentang skalanya adalah:

$$
R s=\frac{100-0}{5} \times 100 \%=20 \%
$$

sehingga kriteria kepuasannya adalah sebagai berikut:

Tabel 2. Nilai dan Kriteria CSI

\begin{tabular}{ll}
\hline \multicolumn{1}{c}{ Nilai CSI } & \multicolumn{1}{c}{ Kriteria CSI } \\
\hline $0 \%<$ CSI $\leq 20 \%$ & Sangat tidak puas \\
$20 \%<$ CSI $\leq 40 \%$ & Tidak puas \\
$40 \%<$ CSI $\leq 60 \%$ & Cukup puas \\
$60 \%<$ CSI $\leq 80 \%$ & Puas \\
$80 \%<$ CSI $\leq 100 \%$ & Sangat puas \\
\hline Sumber: Nurmalina dan Astuti, 2012
\end{tabular}


3. Importance Performance Analysis (IPA)

Metoda IPA pertama kali diperkenalkan oleh Martilla dan James (1977) dengan tujuan untuk mengukur kepuasan pelanggan dalam produk atau servisnya. Menurut Simamora (2004), IPA adalah suatu teknik yang digunakan untuk mengukur dimensi-dimensi atau atribut-atribut dari tingkat kinerja yang diharapkan dengan tingkat kepentingan pengunjung. Teknik ini sangat berguna bagi pengembangan strategi pemasaran.

Pada teknik IPA, terdapat dua variabel yang digunakan yaitu $\mathrm{X}$ yang mewakili tingkat kinerja yang dapat memberikan kepuasan pengunjung dan $\mathrm{Y}$ yaitu tingkat kepentingan pengunjung. Langkah-langkah dalam teknik IPA adalah sebagai berikut:

a. Menentukan skor dari setiap indikator variabel $\mathrm{X}$ dan $\mathrm{Y}$ dengan mengalikan seluruh frekuensi data dengan bobotnya. Skor untuk tingkat kepentingan dan kinerja menggunakan tingkat skala Likert dimana sangat baik/sangat penting diberi skor 5 , baik/penting skor 4 , biasa skor 3 , kurang baik/kurang penting skor 2, dan tidak baik/tidak penting diberi skor 1 .

b. Langkah kedua, membagi jumlah skor dengan banyaknya responden, hasilnya berupa skor rata-rata tingkat kepentingan dan skor rata-rata tingkat kinerja setiap atribut dapat dirumuskan sebagai berikut:

$$
\begin{aligned}
& \dot{X}=\frac{\sum \mathrm{X}_{\mathrm{i}}}{n} \\
& \dot{\mathrm{Y}}=\frac{\sum \mathrm{Y}_{\mathrm{i}}}{n}
\end{aligned}
$$

Keterangan:

$\dot{X}=$ skor rata-rata tingkat kinerja

$\dot{Y}=$ skor rata-rata tingkat kepentingan

$\Sigma \mathrm{X}_{\mathrm{i}}=$ total skor tingkat kinerja

$\Sigma Y_{\mathrm{i}}=$ total skor tingkat kepe ntingan

$\mathrm{n}=$ jumlah responden

c. Selanjutnya, skor rata-rata tingkat kepentingan dan kinerja diplotkan pada diagram kartesius IPA yang dapat dilihat pada gambar 1. Diagram kartesius tersebut adalah suatu bangun yang dibagi menjadi empat bagian yang dibatasi oleh dua buah garis yang berpotongan tegak lurus pada suatu titik (Ẍ, Ÿ). Rumusnya:

$$
\begin{aligned}
\ddot{X} & =\frac{\sum_{i=1}^{n} \dot{X}_{i}}{K} \\
\ddot{Y} & =\frac{\sum_{i=1}^{n} \dot{Y}_{i}}{K}
\end{aligned}
$$

Keterangan:

$\ddot{\mathrm{X}}=$ rata-rata dari skor rata-rata tingkat kinerja

$\ddot{Y}=$ rata-rata skor rata-rata tingkat kepentingan

$\mathrm{K}=$ banyaknya atribut dalam penelitian

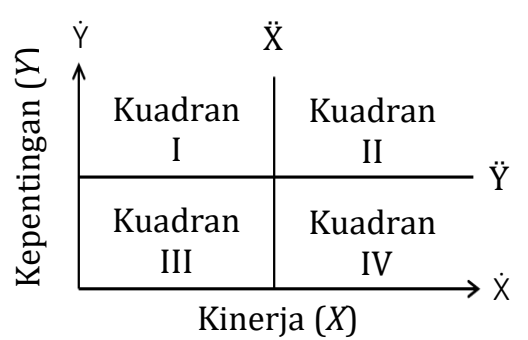

\section{Gambar 1. Diagram Kartesius IPA}

Sumber: Martilla dan James, 1977

\section{HASIL DAN PEMBAHASAN}

\section{GAMBARAN UMUM PROGRAM AGROEDUWISATA TTP CIGOMBONG}

Program agroeduwisata merupakan salah satu program bisnis yang dilaksanakan TTP Cigombong selain program agribisnis dan program pelatihan. Program agroeduwisata yang dilaksanakan TTP Cigombong terdiri dari 2 paket kegiatan yaitu:

1. Paket berkebun dan fun farming: kegiatan pembakaran sekam, pembuatan pupuk, berkebun, prakterk persemaian, pindah tanam, panen dan pasca panen

2. Paket Go Green dan Go Farming: kegiatan pengolahan pupuk dari sampah dapur dan sampah organik, memilah sampah, pengolahan sampah organik dan anorganik.

Paket kegiatan agroeduwisata di TTP Cigombong dapat dilaksanakan pada hari Senin sampai dengan Jumat sejak pukul 08.00-16.00 WIB. Perkembangan program agroeduwisata TTP Cigombong saat ini, semakin banyak diminati oleh berbagai lembaga, kunjungan yang semakin bertambah terutama dari lembaga-lembaga pendidikan setingkat TK dan SD. Hal ini dapat dilihat dengan meningkatnya jumlah pengunjung 
yaitu pada tahun 2017 sebanyak 553 orang, pada tahun 2018 sebanyak 1.151 orang dan pada tahun 2019 sebanyak 1.740 orang.

\section{KARASTERISTIK RESPONDEN}

Karakteristik pengunjung merupakan faktor penting yang harus diketahui oleh pengelola agrowisata guna memahami kebiasaan, permintaan, dan kebutuhan pengunjung selama melakukan perjalanan wisata (Arioditha \& Djuendah, 2016). Hasil dari pengolahan kuesioner yang diisi oleh 34 responden pengunjung program agroeduwisata TTP Cigombong pada Tabel 3.

Target konsumen program agroeduwisata TTP Cigombong adalah untuk pelajar khususnya tingkat Taman Kanak-kanak (TK) sampai dengan Sekolah Dasar. Hal ini sesuai dengan hasil kuisioner yang menunjukkan bahwa pengunjung sebagian besar datang bersama rombongan sekolah yaitu sebesar 44 persen. Namun, sesuai kategori yang ditetapkan, bahwa responden memiliki usia minimal 17 tahun, maka responden yang berasal dari kunjungan sekkolah adalah para guru/orang tua/pendamping kelompok pelajar tersebut, sehingga berdasarkan pekerjaannya rata-rata pengnjung adalah pegawai swasta dan wiraswasta (bukan pelajar).

Berdasarkan hasil kuisioner, pengunjung program agroeduwisata TTP Cigombong diminati baik perempuan dan laki-laki. Apabila dilihat dari pekerjaan dan pendapatan rata-rata pengunjung, responden terdiri dari 2 (dua) kelompok pekerjaan yaitu wiraswasta sebesar 35 persen (12 orang) dan pegawai swasta (khususnya guru) sebesar 29 persen (10 orang) dengan sebagian besar pendapatan adalah pendapatan 1-4 juta sebesar 55,88 persen (19 orang). Hal ini menunjukkan bahwa agroeduwisata TTP Cigombong merupakan lokasi tujuan wisata yang memiliki harga yang terjangkau.

\section{TINGKAT KEPUASAN PENGUNJUNG}

Berdasarkan perhitungan nilai CSI program agribisnis sebesar 78,79\%. Merujuk pada tabel 4, nilai CSI yang didapatkan program agroeduwisata TTP Cigombong menunjukkan bahwa secara keseluruhan pengunjung program agroeduwisata TTP Cigombong merasa puas terhadap kinerja program agroeduwisata TTP Cigombong. Hasil pengisian kuisioner secara terbuka menunjukkan pengun-jung merasa puas dengan program agroeduwisata yang dijalankan TTP Cigombong karena program wisata yang ditawarkan TTP Cigombong dapat menambah ilmu pengetahuan di bidang pertanian dan peternakan dengan fasilitas penunjang yang lengkap, pelayanan dari pemandu yang ramah dan lokasi yang bersih dan nyaman.

Tabel 3. Karakteristik Pengunjung Program Agroeduwisata

\begin{tabular}{lcc}
\hline \multicolumn{1}{c}{ Keterangan } & Jumlah Orang & Persentase \\
\hline A. Jenis Kelamin & & 53 \\
\hline Perempuan & 18 & 47 \\
Laki-laki & 16 & 9 \\
\hline B. Pekerjaan & 3 & 29 \\
\hline Pegawai Negeri Sipil/TNI & 10 & 35 \\
Pegawai Swasta & 12 & 15 \\
Wiraswasta & 5 & 23 \\
Ibu Rumah Tangga & & 56 \\
\hline C. Rata-rata Pendapatan & 8 & 12 \\
\hline$<1.000 .000$ & 19 & 9 \\
1.000.000 - 4.000.000 & 4 & 18 \\
4.000.001 - 7.000.000 & 3 & 23 \\
$>7.000 .001$ & & 44 \\
\hline D. Sifat Kunjungan & 6 & 15 \\
\hline Sendiri & 8 & \\
Keluarga & 15 & \\
Sekolah & 5 & \\
Kantor & & \\
\hline
\end{tabular}


Tabel 4. Nilai Rataan Penilaian Tingkat Harapan dan Tingkat Kinerja Program Agroeduwisata TTP Cigombong

\begin{tabular}{lcccc}
\hline \multicolumn{1}{c}{ Atribut } & $\begin{array}{c}\text { Mean } \\
\text { Importance } \\
\text { Score (MIS) }\end{array}$ & $\begin{array}{c}\text { Mean } \\
\text { Satisfaction } \\
\text { Score (MSS) }\end{array}$ & $\begin{array}{c}\text { Wight } \\
\text { Factor } \\
\text { (WF) }\end{array}$ & $\begin{array}{c}\text { Weight } \\
\text { Score } \\
\text { (WS) }\end{array}$ \\
\hline Harga tiket & 3,529 & 3,676 & 0,057 & 0,208 \\
Manfaat Agroeduwisata & 4,176 & 4,206 & 0,067 & 0,282 \\
Promosi & 4,088 & 3,824 & 0,066 & 0,251 \\
Kecepatan pemandu melayani pengunjung & 4,176 & 3,971 & 0,067 & 0,266 \\
Respons terhadap keluhan pengunjung & 4,147 & 3,824 & 0,067 & 0,254 \\
Kenyamanan lokasi & 4,235 & 3,941 & 0,068 & 0,268 \\
Keamanan lokasi & 4,235 & 3,912 & 0,068 & 0,266 \\
Kesopanan dan keramahan pemandu & 4,353 & 4,088 & 0,070 & 0,286 \\
Kemudahan komunikasi & 4,206 & 4,029 & 0,067 & 0,272 \\
Kemudahan akses transportasi & 4,118 & 3,706 & 0,066 & 0,245 \\
Paket kegiatan yang ditawarkan & 4,176 & 3,971 & 0,067 & 0,266 \\
Fasilitas penunjang & 4,235 & 4,088 & 0,068 & 0,278 \\
Fasilitas konsumsi & 4,176 & 3,941 & 0,067 & 0,264 \\
Fasilitas penginapan & 4,176 & 3,765 & 0,067 & 0,252 \\
Kerapihan pemandu & 4,294 & 4,088 & 0,069 & 0,282 \\
\hline Jumlah & 62,324 & 59,029 & 1,000 & 3,939 \\
\hline \multicolumn{1}{c}{ Customer Satisfaction Index (CSI) } \\
\hline
\end{tabular}

Sumber: Data Primer Diolah, 2020

Meskipun demikian, program agroeduwisata TTP Cigombong tetap perlu meningkatkan kinerjanya karena masih terdapat 21,21 persen dari kepuasan pengunjung yang belum dipenuhi oleh pihak TTP Cigombong. Salah satunya, dengan cara memperbaiki atribut-atribut yang dinilai pelanggan kurang memuaskan dengan pendekatan IPA.

\section{IDENTIFIKASI TINGKAT KEPENTINGAN PENGUNJUNG DAN TINGKAT KINERJA PROGRAM AGROEDUWISATA TTP CIGOMBONG}

Peningkatan kepuasan pengunjung dapat dilakukan melalui peningkatan tingkat kinerja atribut karena tingkat kepentingan atribut sangat tergantung dari kepentingan pengunjung. Prioritas perbaikan kinerja produk dapat dilakukan dengan menggunakan analisis IPA. Analisis IPA meletakkan atribut-atribut yang diuji ke dalam empat kuadran kartesius yaitu kuadran I, kuadran II, kuadran III dan kuadran IV. Menurut Aryanti \& Rosinta (2010), perbaikan kualitas pelayanan dapat dilakukan secara bertahap berdasarkan prioritas perbaikannya yang dijabarkan pada diagram Kartesius. Pemetaan setiap atribut-atribut tersebut berdasarkan rata-rata skor tingkat kepentingan dan skor rata-rata tingkat kepuasan yang diperoleh pada Tabel 5 .

Berdasarkan tabel 5. skor rata-rata ratarata tingkat kinerja (Ẍ) sebesar 3,935 dan skor rata-rata rata-rata tingkat kepentingan ( sebesar 4,155 dijadikan sebagai garis berpotongan yang membagi diagram menjadi 4 (empat) kuadran. Selanjutnya, garis tersebut digunakan untuk menentukan posisi 15 atribut tingkat kinerja dan tingkat kepentingan sesuai nilai rata-rata tingkat kinerja $(\dot{X})$ dan rata-rata tingkat kepentingannya (Yं) seperti Gambar 2.

\section{Kuadran I (Atribut Prioritas Utama)}

Kuadran I menunjukkan atribut yang dianggap sangat penting oleh pengunjung program agroeduwisata TTP Cigombong namun tingkat kinerja dari program agroeduwisata TTP Cigombong belum sesuai dengan yang diharapkan pengunjung sehingga menimbulkan rasa tidak puas pengunjung. Atribut yang berada di kuadran I menjadi prioritas utama bagi pihak TTP Cigombong untuk memperbaiki tingkat kinerja atribut dalam rangka memenuhi kepentingan pengunjung sehingga kepuasan pengunjung dapat tercapai. Berdasarkan hasil penelitian, terdapat 2 (dua) atribut pada program agroeduwisata yang berada pada kuadran I karena memiliki nilai 
Tabel 5. Nilai Rataan Penilaian Tingkat Kepentingan dan Tingkat Kinerja Program Agroeduwisata TTP Cigombong

\begin{tabular}{lcc}
\hline \multicolumn{1}{c}{ Atribut } & $\begin{array}{c}\text { Rata-rata Tingkat } \\
\text { Kepentingan }(\dot{Y})\end{array}$ & $\begin{array}{c}\text { Rata-rata Tingkat } \\
\text { Kinerja }(\dot{X})\end{array}$ \\
\hline Harga tiket & 3,529 & 3,676 \\
Manfaat Agroeduwisata & 4,176 & 4,206 \\
Promosi & 4,088 & 3,824 \\
Kecepatan pemandu melayani pengunjung & 4,176 & 3,971 \\
Respons terhadap keluhan pengunjung & 4,147 & 3,824 \\
Kenyamanan lokasi & 4,235 & 3,941 \\
Keamanan lokasi & 4,235 & 3,912 \\
Kesopanan dan keramahan pemandu & 4,353 & 4,088 \\
Kemudahan komunikasi & 4,206 & 4,029 \\
Kemudahan akses transportasi & 4,118 & 3,706 \\
Paket kegiatan yang ditawarkan & 4,176 & 3,971 \\
Fasilitas penunjang & 4,235 & 4,088 \\
Fasilitas konsumsi & 4,176 & 3,941 \\
Fasilitas penginapan & 4,176 & 3,765 \\
Kerapihan pemandu & 4,294 & 4,088 \\
\hline Rata-rata & 4,155 & 3,935 \\
Sumber: Data Primer Diolah, 2020 & &
\end{tabular}

tingkat kepentingan rata-rata lebih dari 4,155 dan nilai tingkat kinerja rata-rata kurang dari 3,935 yaitu atribut keamanan lokasi dan fasilitas penginapan (Gambar 2).

Pengunjung memiliki tingkat kepentingan yang tinggi terhadap atribut keamanan lokasi karena pengunjung dapat menikmati kegiatan agroeduwisata dengan aman dari bahaya atau risiko dan keragu-raguan saat mereka melakukan kegiatan agroeduwisata. Hal ini sesuai yang disampaikan Prayudi, et al (2019), pada agrowisata yang konsumen utamanya adalah anakanak, atribut keamanan akan dinilai sangat penting karena pada kemanan lokasi wisata yang memadai membuat orang tua akan merasa tenang melepaskan anaknya untuk mengikuti kegiatan wisata didalam lokasi bersama dengan guru. Berdasarkan hasil penelitian, pengunjung menilai kinerja atribut keamanan lokasi program agroeduwiisata TTP Cigombong kurang baik, karena perangkat keamanan di TTP Cigombong masih dibawah standar keamanan lokasi wisata pada umumnya, diantaranya pada siang hari gerbang masuk TTP Cigombong belum dijaga petugas keamanan dan ruangan tempat pengunjung agroeduwisata berkumpul belum dilengkapi dengan kamera CCTV. Menurut Fitrianti, et al (2015), kualitas pelayanan yang berfokus pada kemampuan untuk melahirkan kepercayaan dan keyakinan pada diri pelanggan akan menyebabkan pengunjung merasa puas. Sedangkan dengan fasilitas keamanan yang terbatas tersebut, pengunjung belum merasa puas. Hasil penelitian ini dapat menjadi masukan bagi TTP Cigombong, apabila mau meningkatkan jumlah pengunjung program agroeduwisata agar meningkatkan fasilitas untuk keamanan lokasi TTP Cigombong.

Pada atribut fasilitas penginapan, pengunjung memiliki kepentingan sesuai dengan hasil penelitian yang memilki nilai rata-rata di atas tingkat kepentingan rata-rata. Hal ini disebabkan lokasi TTP Cigombong tidak berada di tengah kota sehingga pengunjung berpotensi untuk melakukan penginapan ketika melakukan agroeduwisata ke TTP Cigombong. Selain itu, lokasi TTP Cigombong berada pada kawasan lingkungan yang sejuk, sehingga mendukung pengunjung untuk menikmati keindahan malam di TTP Cigombong. Namun, saat ini fasilitas penginapan yang tersedia di TTP Cigombong berupa mess atau penginapan di rumah penduduk sekitar, sehingga pengunjung menilai kinerja atribut faslitas penginapan belum cukup baik yaitu masih dibawah tingkat kinerja rata-rata.

\section{Kuadran II (Atribut Pertahankan Prestasi)}

Kuadran II menunjukkan atribut yang dianggap penting oleh pengunjung (nilai Ỷ lebih 


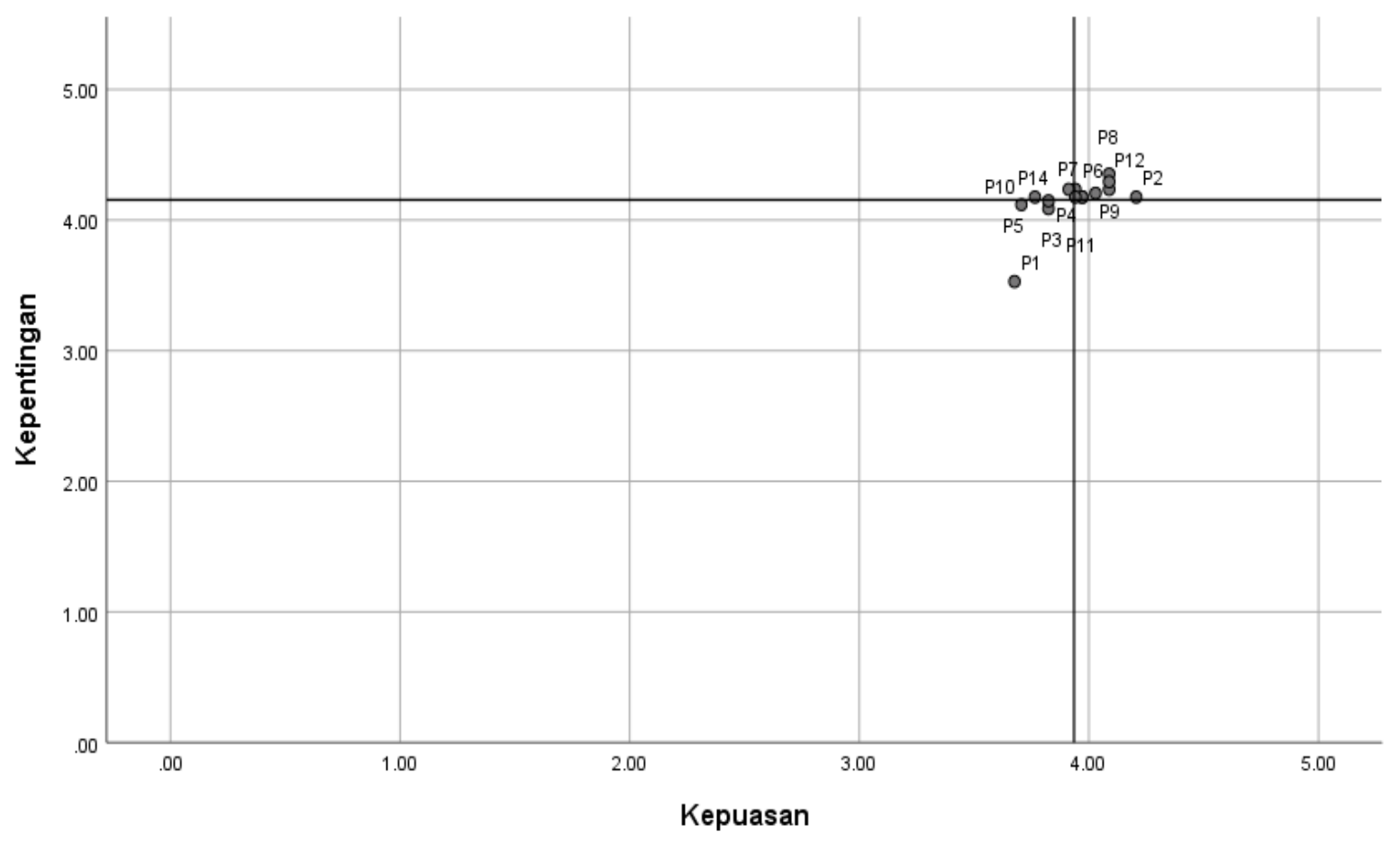

Keterangan: Kuadran I

1. Keamanan lokasi (P7)

2. Fasilitas penginapan (P14)

\author{
1. Manfaat Agroeduwisata (P2) \\ 2. Kecepatan pemandu (P4) \\ 3. Kenyamanan lokasi (P6) \\ 4. Kesopanan dan keramahan pemandu (P8) \\ 5. Kemudahan akses transportasi (P10) \\ 6. Paket kegiatan yang ditawarkan (P11) \\ 7. Fasilitas penunjang (P12) \\ 8. Fasilitas konsumsi (P13) \\ 9. Kerapihan pemandu (P15)
}

1. Harga tiket agroeduwisata (P1)

2. Promosi (P3)

3. Respons terhadap keluhan pengunjung (P5)

4. Kemudahan penyelenggaraan kegiatan (P9)

\section{Gambar 2. Diagram Kartesius Importance Performance Analysis (IPA)}

Sumber: Data primer (2020)

dari 4,155) dan memiliki tingkat kinerja yang baik (nilai $\dot{X}$ lebih dari 3,935) sehingga membuat pengunjung puas. Hal ini menunjukkan program agroeduwisata TTP Cigombong harus mempertahankan prestasinya dengan menjaga kualitas kinerja pada atribut-atribut yang termasuk didalamnya. Berdasarkan hasil penelitian, kuadran II merupakan kuadran yang paling banyak atribut yang didalamnya, yaitu sebanyak 9 (sembilan) atribut. Atribut-atribut yang termasuk pada kuadran II pada program agroeduwisata adalah manfaat agroeduwisata, kecepatan atau ketanggapan pemandu melayani pengunjung, kenyamanan lokasi, kesopanan dan keramahan pemandu, kemudahan komunikasi untuk penyelenggaraan kegiatan, paket kegiatan agroeduwisata yang ditawarkan, fasilitas penunjang agroeduwisata (sarana toilet, ibadah, dll), fasilitas konsumsi, kerapihan pemandu.

Atribut manfaat agroeduwisata telah dinilai pengunjung memiliki kinerja yang baik sesuai dengan jawaban yang terbuka responden bahwa motivasi sebagian besar pengunjung adalah untuk belajar pertanian dan peternakan dan manfaat yang paling dirasakan setelah mengikuti program agroeduwisata di TTP Cigombong adalah menambah ilmu tentang pertanian dan peternakan.

Atribut kecepatan pemandu melayani pengunjung, atribut kenyamanan lokasi, atribut kesopanan dan keramahan serta atribut kemudahan komunikasi untuk menyelenggarakan kegiatan agroeduwisata merupakan atribut yang berhubungan langsung dengan sikap dan pelayanan yang dilakukan pegawai TTP Cigombong. 
Pengunjung menilai program agroeduwisata TTP Cigombong telah memiliki kinerja yang baik atribut-atribut tersebut menunjukkan TTP Cigombong memiliki pegawai yang mendukung untuk menjalankan program agroeduwisata. Pemandu agroeduwisata TTP Cigombong dinilai telah melakukan komunikasi dan mendampingi pengunjung dalam program agroeduwisata dengan sikap yang sopan dan ramah. Hal ini harus dipertahankan oleh TTP Cigombong yang melaksanakan program agroeduwisata. Sebagaimana yang disampaikan oleh Setiawan (2016) bahwa pada sektor pariwisata, perusahaan memiliki hubungan langsung yang bersifat intangible (tak berwujud) dengan konsumen, sehingga sangat bergantung pada kemampuan individu karyawan atau pegawai dalam membangkitkan minat dan menciptakan kesenangan serta kenyamanan kepada para konsumennya. Selain itu, menurut Prawiranata, et al (2016) pelanggan akan memberikan nilai kepuasan yang signifikan apabila mendapat perhatian yang tulus dan bersifat individual atau pribadi dari pegawai yang berupaya memahami keinginan pelanggan.

Atribut paket kegiatan agroeduwisata yang ditawarkan, fasilitas penunjang agroeduwisata (sarana toilet, ibadah, dll), fasilitas konsumsi, kerapihan pemandu merupakan atribut-atribut dimensi tangible (bukti langsung). Pengunjung menilai penting dan program agroeduwisata TTP Cigombong telah memiliki kinerja yang memuaskan pada atribut-atribut tersebut dalam pelaksanaan program agroeduwisata TTP Cigombong. Hal ini sesuai dengan simpulan dalam penelitian Irmanda (2012) yang menyatakan bahwa tempat wisata yang baik harus terjaga kebersihan dan keamanannya, memberikan sarana dan prasarana yang lengkap, dapat menambah pengetahuan pengunjung serta memberikan fasilitas dan program wisata yang benar-benar dijalankan seperti kelengkapan pada paket agrowisata yang ditawarkan dengan menambahkan proses penanaman hingga proses hasil panen.

\section{Kuadran III (Atribut Prioritas Rendah)}

Kuadran III pada diagram kartesius IPA menunjukkan atribut yang dianggap kurang penting oleh pengunjung (nilai $\dot{Y}$ kurang dari
4,155) dan kinerja program agroeduwisata TTP Cigombong juga tidak cukup baik (nilai Ẋ kurang dari 3,935). Perbaikan atau peningkatan kinerja pada atribut yang termasuk pada kuadran III menjadi prioritas rendah untuk ditingkatkan karena pengaruhnya kecil terhadap kepuasan pengunjung. Meskipun demilikan, TTP Cigombong tetap perlu mewaspadai, mencermati dan mengontrol atribut yang ada pada kuadran ini, karena meningkatnya persaingan dari kompetitor dan perkembangan sosial, ekonomi serta teknologi dapat merubah tingkat kepentingan pengunjung. Atribut-atribut yang termasuk pada atribut prioritas rendah pada program agroeduwisata adalah harga tiket agroeduwisata, promosi yang dilakukan TTP Cigombong, respons terhadap keluhan pengunjung dan kemudahan akses transportasi mencapai lokasi.

Berdasarkan tabel 5 dan gambar 2, nilai rata-rata kinerja $(\dot{X})$ dan nilai rata-rata kepentingan $(\dot{Y})$ atribut harga tiket agroeduwisata nilainya sangat lebih rendah dari nilai rata-rata rata-rata kinerja $(\ddot{X})$ dan nilai rata-rata rata kepentingan (Ÿ) seluruh atribut yang dinilai pada program agroeduwisata. Hal ini menunjukkan pengunjung program agroeduwisata TTP Cigombong menilai atribut harga tiket kurang penting dan harga tiket yang ditawarkan sekarang ini belum cukup baik. Menurut Nursinggih dan Apriatni (2018) penilaian kepuasan terkait harga oleh pengunjung akan ditentukan oleh manfaat yang diterima pengunjung dan pelayanan yang diberikan oleh objek wisata sejenis yang mematok harga lebih mahal. Oleh karena itu, untuk meningkatkan kepuasan pengunjung pada atribut harga tiket, TTP Cigombong dapat meningktkan manfaat yang dapat diterima oleh pengunjung dari mengikuti program agroeduwisata di TTP Cigombong.

Atribut promosi yang dilakukan memiliki tingkat kepentingan yang rendah karena berdasarkan pengisian kuisioner terbuka pengunjung mendapatkan informasi dari keluarga atau teman. Hal ini sesuai dengan penelitian Irmanda (2012) bahawa terbentuknya positif words of mouth akan memudahkan tenaga pemasar untulk meningkatkan jumlah wisatawan. Pada kinerja promosi yang dilakukan program agroeduwisata TTP Cigombong dinilai belum 
memiliki kinerja yang baik karena promosi yang dilakukan memang belum secara intensif dilaksanakan, yaitu berupa penerbitan pamflet, media sosial berita-berita terkait program agroeduwisata pada website Pemda Kabupaten Bogor dan website Badan Litbang Kementerian Pertanian. Namun, walaupun pengunjung menilai kepentingan terhadap promosi rendah, seiring dengan meningktnya jumlah destinisai wisata di Kabupaten Bogor dan untuk meningkatkan jumlah pengunjung pada program agroeduwisata, TTP Cigombong harus juga meningkatkan kinerja pada atribut promosi. Salah satu cara efektif untuk memasarkan objek wisata adalah promosi yaitu dengan iklan melalui media sosial. Data Asosiasi Penyelenggara Jasa Internet Indonesia (APJII) tahun 2018 menunjukkan sebanyak 171,17 juta dari 264,16 juta penduduk Indonesia telah menggunakan internet dan 97,4 persen diantaramya untuk mengakses media sosial (Ardianti dan Lubis, 2020). Selain itu, hasil penelitian Oktaviani dan Fatchiya (2019) menunjukkan bahwa penggunaan media sosial sebagai media promosi efektif untuk mempromosikan objek wisata.

Atribut respons terhadap keluhan pengunjung atribut tidak dinilai penting oleh pengunjung dan kenyataan empirisnya pun dinilai belum cukup baik. Rendahnya kepentingan terhadap atribut ini disebabkan kinerja pada 9 (sembilan) atribut yang sudah baik sehingga pengunjung tidak banyak melakukan keluhan pada program agroeduwisata.

Pada atribut kemudahan akses transportasi mencapai lokasi dinilai tidak cukup penting dan tidak cukup baik oleh responden karena berdasarkan karakteristik responden dimana sebagian besar pengunjung yang datang adalah rombongan baik dari keluarga, sekolah, universitas maupun kantor sehingga pada umumnya menggunakan kendaraan yang langsung bisa mencapai lokasi TTP Cigombong. Sedangkan kemudahan akses transportasi dinilai belum cukup baik karena untuk mencapai lokasi TTP Cigombong harus melewati jalan yang tidak terlalu lebar

\section{Kuadran IV (Atribut Berlebihan)}

Kuadran ini menunjukkan faktor-faktor yang dianggap kurang penting oleh pengunjung tetapi kinerja yang dihasilkan oleh TTP Cigombong sangat baik atau sangat memuaskan, sehingga pengunjung menilai produk tersebut terlalu berlebihan. Berdasarkan hasil penelitian, tidak ada atribut penilaian yang memiliki nilai rata-rata kepentingannya kurang dari 4,155 dan nilai rata-rata kinerja program agroeduwisata TTP Cigombong lebih dari 3,935. Hal ini menunjukkan program agroeduwisata TTP Cigombong tidak memiliki kinerja yang baik pada atribut yang dinilai tidak penting oleh pengunjung.

\section{SIMPULAN DAN SARAN}

\section{SIMPULAN}

1. Pengunjung program agroeduwisata TTP Cigombong merasa puas dengan kinerja program agroeduwisata TTP Cigombong dengan nilai CSI sebesar 78,79\%.

2. Berdasarkan matriks IPA untuk meningkatkan kepuasan pengunjung program agroeduiwsata TTP Cigombong, atribut yang menjadi prioritas untuk diperbaiki adalah atribut keamanan lokasi dan fasilitas penginapan. Atribut yang harus dipertahankan kinerjanya adalah manfaat agroeduwisata, kecepatan atau ketanggapan pemandu melayani pengunjung, kenyamanan lokasi, kesopanan dan keramahan pemandu, kemudahan komunikasi untuk penyelenggaraan kegiatan, paket kegiatan agroeduwisata yang ditawarkan, fasilitas penunjang agroeduwisata (sarana toilet, ibadah, dll), fasilitas konsumsi, kerapihan pemandu. Atribut yang harus diperbaiki kinerjanya dengan priioritas rendah adalah harga tiket agroeduwisata, promosi yang dilakukan, respons terhadap keluhan pengunjung dan kemudahan akses transportasi mencapai lokasi.

\section{SARAN}

1. Pengelola TTP Cigombong harus melakukan peningkatan kualitas dan kinerja program agroeduwisata untuk meningkatkan kepuasan pengunjung program agroeduwisata. 
2. Sesuai dengan hasil penelitian, pengelola TTP Cigombong disarankan agar memprioritaskan anggaran pengembangan TTP Cigombong yang tersedia untuk menyediakan dan meningkatkan fasilitas keamanan di lokasi seperti penyediaan CCTV dan penyediaan fasilitas penginapan yang representatif bagi pengunjung.

\section{DAFTAR PUSTAKA}

Ardianti, F dan Lubis, D., P. (2020). Ekektivitas Instagram Sebagai Media Promosi Desa Wisata Malasari, Kecamatan Nanggung, Kabupaten Bogor. Jurnal Sains Komunikasi dan Pengembangan Masyarakat [JSKPM], 4 (6):796-809. DOI: http://ejournal.skpm.ipb.ac.id/index.php/js $\mathrm{kpm} /$ article/view/739/pdf

Arioditha G dan Djuwendah E. (2016). Analisis Kepuasan Pengunjung Berkunjung ke Agrowisata dengan Konsep Edufarming di PT. Jendela Alam Parongpong Kabupaten Bandung Barat. AGRICORE-Jurnal Agribisnis dan Sosial Ekonomi Pertanian, 1(1), 42-48. DOI:

http://jurnal.unpad.ac.id/agricore/article/v iew $/ 22688 /$ pdf

Aritonang, R.L. 2005. Kepuasan Konsumen. Jakarta (ID): Gramedia.

Aryanti, D dan Rosinta, F. (2010). Pengaruh Kualitas Layanan terhadap Kepuasan Pelanggan dalam Membentuk Loyalitas Pelanggan. Jurnal Bisnis \& Birokrasi, Jurnal Ilmu Administrasi dan Organisasi, 17(2), 114126. DOI: http://journal.ui.ac.id/index.php/jbb/article /view/632/617

Baker, DA, and Crompton, JL. (2000). Quality, Satisfaction and Behavioural Intentions", Annals of Tourism Research, 27 (3): 785-804.

[BPATP] Balai Pengelola Alih Teknologi Pertanian. 2015. Grand Design Taman Teknologi Pertanian Kabupaten Bogor. Bogor.

[BPATP] Balai Pengelola Alih Teknologi Pertanian. 2017. Laporan Tengah Tahun Pembangunan Taman Teknologi Pertanian. Bogor.
Fitrianti, S., Ismawati, I., dan Silia, N. (2015). Analisis Tingkat Kepuasan Pengunjung Kawasan Wisata Lembah Harau. Jurnal $\begin{array}{llll}\text { Polibisnis, } & 7 & \text { (1), 37-46. } & \text { DOI: }\end{array}$ https://core.ac.uk/download/pdf/2680974 26.pdf

Irawan, H. 2003. 10 Prinsip Kepuasan Pelanggan. Jakarta (ID): PT Elex Media Computindo.

Irmanda, S. M. (2012). Analisis Pengaruh Keberagaman Program Wisata, Mutu Program Wisata dan Mutu Pelayanan Terhadap Kepuasan Wisatawan Dalam Meningkatkan Positif Words of Mouth (Studi pada Agrowisata Kebun Buah Plantera Fruit Paradise, Desa Sidokumpul, Kecamatan Patean, Kabupaten Kendal. Jurnal Sains Pemasaran Indonesia, 11 (3), 232-258. DOI: https://ejournal.undip.ac.id/index.php/ispi Larticle/view/14313/10901

Jeneetica, M. (2018). Kepuasan Wisata Pada Destinasi Agrowisata di Bogor. National Conference of Creative Industry: Sustainable Tourism Industry for Economic Development, 49-55. DOI: file:///C:/Users/User/Downloads/11974405-1-PB.pdf

Kotler, P. 2002. Manajemen Pemasaran: Analisis Perencanaan Implementasi dan Kontrol. Edisi Milenium, Jakarta (ID): Penerbit PT Prenhalindo.

Martilla, J. A., and James, J. C. (1977). ImportancePerformance Analysis. Journal of Marketing. $41 \quad$ (1), 77-79. DOI: http://www.downloadebooks.ir/Managmen $\mathrm{t}$ (Modiriat)/rozbeh_madadi200/Importance Performance\%20Analysis.pdf.

Ningsih, V.H. dan Prawiranegara, P. 2016. Identifikasi Lokasi Agrowisata di Desa Tugujaya, Kecamatan Cigombong, Kabupaten Bogor. Jurnal Online Mahasiswa (JOM) Bidang Perencanaan Wialayah dan Kota, 1(1). DOI: https://jom.unpak.ac.id/index.php/teknikp $\mathrm{wk} /$ article/view/135

Nurmalina R dan Astuti EP. 2012. Analisis Preferensi dan Kepuasan Konsumen terhadap Beras di Kecamatan Mulyorejo Surabaya Jawa Timur. Jurnal Sains Terapan. 1(1): $\quad 42-47 . \quad$ DOI: https://journal.ipb.ac.id/index.php/istsv/ar $\underline{\text { ticle/view/28242/18015 }}$ 
Nursinggih TF dan Apriatni, (2018). Analisis Kepuasa Pengunjung Objek Wisata Umbul Ponggok Klaten Ditinjau dari Kualitas Pelayanan, Harga dan Promosi. ejournal3.undip.ac.id. DOI https://ejournal3.undip.ac.id/index.php/jia b/article/view/19071/18121

Oktaviani, W. F dan Fatchiya, A. (2019). Efektivitas penggunaan Media Sosial Sebagai Media Promosi Wisata Umbul Ponggok, Kabupaten Klaten. Jurnal Komunikasi Pembangunan, 17 (1), 13-27.

DOI file://C:/Users/User/Downloads/26586Article\%20Text-82371-1-10-20190702.pdf

Parasuraman, A., Berry, Leonard L, and Zeithaml, Valarie A. (1988). "SERVQUAL: AMultipleItem Scale for Measuring Consumer Perceptions of Service Quality". Journal of Retailing, 64 (Spring), 12-40.

Prayudi, A. B. E. D., Dolorosa E, Kurniati D. (2019). Kepuasan Pengunjung Terhadap Agrowisata di Agribisnis Aloe Vera Center. Jurnal Ilmu Pertanian, 31 (1), 15-30. DOI: file://C:/Users/User/Downloads/1978Article\%20Text-9561-2-10-20190801.pdf

Prawiranata, A., Yulianto, E., Kusumawati, A. 2016. Pengaruh Keramahtamahan dan kualitas Pelayanan Terhadap Kepuasan Pelanggan (Survei pada Pelanggan Villa Agrowisata Kebun Teh Wonosari Lawang, Malang). Jurnal Administrasi Bisnis , 32 (1), 114-120. DOI:

file:///C:/Users/User/Downloads/12464960-1-PB.pdf

Rahayu dan Nurharjadmo. (2017). Evaluasi Implementasi Program Pengembangan Solo Technopark. Jurnal Wacana Publik, 1(6), 4857.

DOI:

file://C:/Users/User/Downloads/18034131317-1-PB.pdf

Setiawan, R I. (2016). Pengembangan Sumber Daya Manusia di Bidang Pariwisata: Perspektif Potensi Wisata Daerah Berkembang. Jurnal Penelitian Manajemen Terapan (PENATARAN), 1 (1): 23-35. DOI: file://C:/Users/User/Downloads/301Article\%20Text-431-1-1020170911\%20(1).pdf
Simamora, B. 2004. Panduan Riset Perilaku Konsumen. Jakarta (ID): Gramedia Pustaka Utama.

Sugiarto DS. 2003. Metode Statistika untuk Bisnis dan Ekonomi. Jakarta (ID): Penerbit PT. Gramedia Pustaka Utama.

Sugiyono. 2011. Metode Penelitian Kuantitatif, kualitatif dan $R \& D$. Bandung (ID): Alfabeta.

Sumarwan, Ujang. 2014. Perilaku Pengunjung: buku materi pokok EKMA 5317/3 sks/ Modul $1 . \quad$ DOI https://www.pustaka.ut.ac.id/lib/wpcontent/uploads/pdfmk/EKMA456702M1.pdf

Tjiptono, Fandy. 2006. Manajemen Pemasaran Jasa. Penerbit Andi, Jogyakarta.

Tjiptono F dan Chandra. 2012. Kepuasan konsumen dan kepuasan pelanggan. Edisi 2. Jakarta (ID): PT Gramedia Pustaka Utama. 